Gillilan, L. A. (1955). Clinical Aspects of the Autonomic Nervous System. London, Churchill.

Greenhalgh, R. M., Rosengarten, D. S., and Martin, P. (1971). British Medical fournal, $1,332$.

Guttmann, L. (1947). Postgraduate Medical fournal, 23, 353.

Hannington, E. (1967). British Medical fournal, 1, 550.

Haxton, H. A. (1948). Brain, 71, 16.

Herxheimer, A. (1958). British Medical fournal, 1, 688.

Keen, H. (1959). Postgraduate Medical Fournal, 35, 272.

Lee, T. S. (1954). Fournal of Physiology, 124, 528.

List, C. F., and Peet, M. M. (1938). Archives of Neurology and Psychiatry, 40,443 .
Monro, P. A. G. (1959). Sympathectomy. London, Oxford University Press. Murray, J. G., and Thompson, J. W. (1957). British Medical Bulletin, 13,

Parkes Weber, F. (1947). Rare Diseases and Some Debatable Subjects, 2nd edn. London, Staple Press.

Pick, J. (1970). The Autonomic Nervous System. Philadelphia, Lippincott. Rundles, R. W. (1945). Medicine, 24, 111.

Tankel, H. I. (1951). Fournal of Neurology, Neurosurgery and Psychiatry, 14, 129.

Uprus, V., Taylor, J. B., and Carmichael, E. A. (1934). Brain, 57, 443.

Wilson, W. C. (1936). Clinical Science, 2, 273.

Young, A. G. (1956). British Medical fournal, 2, 976.

\title{
Pharmacological Modification of Gastric Emptying: Effects of Propantheline and Metoclopromide on Paracetamol Absorption
}

\author{
J. NIMMO, R. C. HEADING, P. TOTHILL, L. F. PRESCOTT
}

British Medical fournal, 1973, 1, 587-589

\section{Summary}

The rate of paracetamol absorption depends on the rate of gastric emptying. Propantheline delayed gastric emptying and markedly slowed the absorption of paracetamol in six convalescent hospital patients. Conversely, the absorption of paracetamol in five healthy volunteers was accelerated by metoclopramide, a drug which stimulates gastric emptying. The total 24-hour urinary excretion of paracetamol was not influenced by propantheline or metoclopramide. Other similar absorption interactions probably occur since drugs are poorly absorbed from the stomach and many therapeutic agents influence gastrointestinal motility.

\section{Introduction}

Most drugs are absorbed from the gastrointestinal tract as unionized molecules by passive diffusion. Lipid solubility is an important factor and the rate of transfer is thought to depend on $\mathrm{pH}$ since this determines the fraction of drug present in the unionized lipid soluble state. It is said that weakly acidic drugs are readily absorbed from the acid contents of the stomach while weakly basic drugs are poorly absorbed from this site but are rapidly absorbed from the more alkaline environment of the upper small intestine (Hogben et al., 1957; Schanker et al., 1957; Brodie, 1964). More recent studies have shown, however, that acidic drugs such as warfarin, acetylsalicylic acid, and phenobarbitone are absorbed much more slowly from the stomach than from the small intestine, presumably because the latter has a much larger relative surface area (Siurala et al., 1969; Kekki et al., 1971; Kojima et al., 1971). Contrary to general belief, even easily diffusible neutral compounds of low molecular weight such as ethanol are absorbed more slowly from the stomach than from the small intestine (Magnussen, 1968).

\footnotetext{
University Departments of Therapeutics and Medical Physics, The Royal Infirmary, Edinburgh EH3 9YW

J. NIMMO, B.SC., M.R.C.P., Lecturer in Clinical Pharmacology

R. C. HEADING, B.SC., M.R.C.P., Lecturer in Therapeutics

P. TOTHILL, PH.D., Senior Lecturer in Medical Physics

L. F. PRESCOTT, M.D., F.R.C.P., Senior Lecturer in Clinical Pharmacology
}

The rate of gastric emptying is therefore likely to have important effects on the rate of drug absorption, and in previous studies we have shown that paracetamol absorption in man is related to the rate of gastric emptying (Heading et al., 1973). Propantheline and metoclopramide delay and accelerate gastric emptying respectively, and their influence on the absorption of paracetamol is described in the present report.

\section{Subjects and Methods}

Paracetamol absorption was studied before and after metoclopramide in five healthy ambulant male volunteers aged from 22 to 39 years (mean 31 years) (group A). These subjects were known to be consistently slow absorbers of paracetamol (Prescott and Nimmo, 1971). No other drugs were being taken at the time of investigation. In addition, the effect of propantheline on the kinetics of paracetamol absorption and gastric emptying was investigated in six convalescent hospital patients aged from 22 to 80 years (mean 56 years) (group B). Informed consent was obtained. None had undergone gastrointestinal surgery, and there was no clinical evidence of renal, hepatic, gastrointestinal, or cardiac disease. All other drugs were withheld during the period of investigation.

\section{PARACETAMOL ABSORPTION}

Group A.-After an overnight fast each healthy volunteer ingested $1.5 \mathrm{~g}$ of paracetamol (as three Panadol tablets) with $50 \mathrm{ml}$ of water. The test was repeated not less than one week later, but on this occasion $10 \mathrm{mg}$ of metoclopramide was injected intravenously at the same time as the paracetamol was taken.

Group B.-Simultaneous measurements of gastric emptying rate and paracetamol absorption were made in the patients. After an overnight fast $1.5 \mathrm{~g}$ of paracetamol (Panadol) was taken by mouth with $400 \mathrm{ml}$ of water containing 200 microcuries of $131 m$ In DTPA chelate. Gastric emptying rate was measured by sequential scintiscanning and the result expressed as a half time ( $t \frac{1}{2}$ ) (Heading et al., 1971). At least 48 hours later the whole procedure was repeated 15 minutes after intravenous injection of $30 \mathrm{mg}$ of propantheline. One patient received paracetamol alone and on subsequent occasions was given paracetamol with propantheline and paracetamol with metoclopramide.

Fluids were withheld for two hours after ingestion of paracetamol and tobacco and food were not allowed for four hours. 
Venous blood was taken at intervals up to eight hours and urine was collected from 0-12 and 12-24 hours. Plasma and urine samples were stored frozen. Unchanged and conjugated paracetamol in plasma and urine was estimated by gas-liquid chromatography (Prescott, 1971). With this method there is no interference by propantheline or metoclopramide.

\section{Results}

\section{PROPANTHELINE}

Propantheline decreased the rate of gastric emptying in all

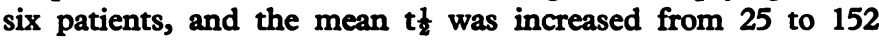
minutes. The mean time taken to reach maximum plasma concentrations of unchanged paracetamol was correspondingly increased from 70 to 160 minutes and the mean maximum concentration was reduced from 26.3 to $17.5 \mu \mathrm{g} / \mathrm{ml}$ (fig. 1 and table I). These differences were statistically significant $(P<0.005)$.

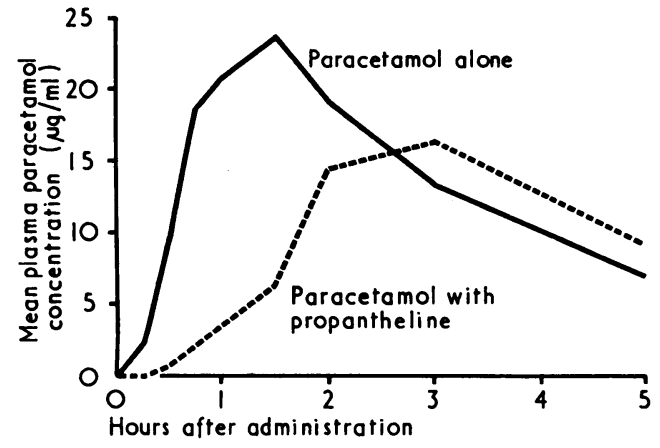

FIG. 1-Inhibitory effect of propantheline on paracetamol absorption in six patients.

TABLE 1-Effect of Propantheline on Gastric Emptying and Paracetamol Absorption in Six Convalescent Patients. Values given are means \pm S.E. of Mean

\begin{tabular}{|c|c|c|c|c|c|}
\hline & \multirow{2}{*}{$\underset{\mathbf{t}_{\mathbf{2}}^{l}(\min )}{\text { Gastric }}$} & \multirow{2}{*}{$\begin{array}{c}\text { Maximum } \\
\text { Plasma } \\
\text { Concen- } \\
\text { tration of } \\
\text { Unchanged } \\
\text { Parace- } \\
\text { tamol } \\
(\mu \mathrm{g} / \mathrm{ml})\end{array}$} & \multirow{2}{*}{$\begin{array}{l}\text { Time of } \\
\text { Peak } \\
\text { Plasma } \\
\text { Concen- } \\
\text { tration } \\
\text { (min) }\end{array}$} & \multicolumn{2}{|c|}{$\begin{array}{l}\text { Urinary Excretion } \\
\text { of Total Unchanged } \\
\text { and Conjugated } \\
\text { Paracetamol }\end{array}$} \\
\hline & & & & $\underset{(\mathrm{mg})}{0-12 \mathrm{hr}}$ & $\underset{(\mathrm{mg})}{0-24 \mathrm{hr}}$ \\
\hline $\begin{array}{l}\text { Before propantheline } \\
\text { After propantheline }\end{array}$ & $\begin{array}{r}25 \pm 9 \\
152 \pm 38\end{array}$ & $\begin{array}{l}26 \cdot 3 \pm 4 \\
17 \cdot 5 \pm 5\end{array}$ & $\begin{array}{r}70 \pm 10 \\
160 \pm 13\end{array}$ & $\begin{array}{l}880 \pm 83 \\
536 \pm 73\end{array}$ & $\begin{array}{l}1,009 \pm 75 \\
1,014 \pm 107\end{array}$ \\
\hline
\end{tabular}

There was no difference in the amount of total unchanged and conjugated paracetamol excreted in the urine in 24 hours, but after propantheline significantly less was excreted in the 0-12 hour period $(P<0.05)$.

\section{METOCLOPRAMIDE}

Maximum plasma concentrations of unchanged paracetamol were higher and appeared earlier after metoclopramide than in the control study in each of the five healthy volunteers (fig. 2 and table II). The mean time taken to reach maximum plasma concentration was reduced from 120 minutes to 48 minutes $(P<0.05)$ while the mean maximum concentration increased from 12.5 to $20.5 \mu \mathrm{g} / \mathrm{ml}(\mathrm{P}<0.05$, one tail test). Metoclopramide did not influence the urinary excretion of paracetamol (table II).

The plasma concentrations of unchanged paracetamol in a 22-year-old man given paracetamol alone and after propantheline and metoclopramide are shown in fig. 3. The $t \frac{1}{2}$ of gastric emptying was increased from a control value of 63 minutes to 300 minutes after propantheline, and there was a corresponding

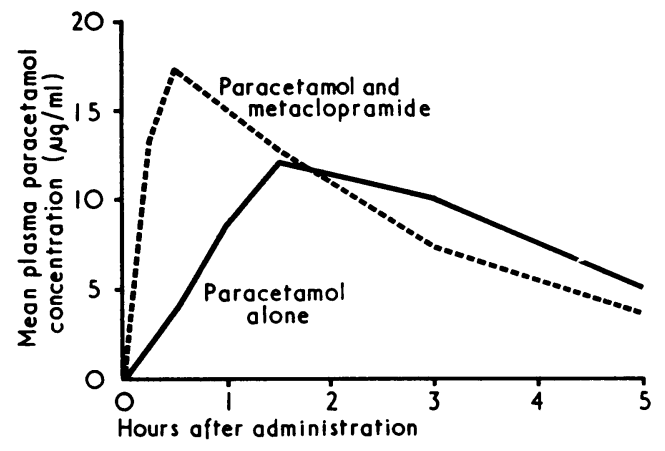

FIG. 2-Increased rate of paracetamol absorption after metoclopramide in five healthy volunteers.

TABLE II-Effect of Metoclopramide on Paracetamol Absorption in Five Healthy Volunteers. Values given are means \pm S.E. of Mean

\begin{tabular}{|c|c|c|c|c|}
\hline & \multirow{2}{*}{$\begin{array}{c}\text { Maximum } \\
\text { Plasma } \\
\text { Concentra- } \\
\text { tion of } \\
\text { Unchanged } \\
\text { Paracetamol } \\
(\mu \mathrm{g} / \mathrm{ml})\end{array}$} & \multirow{2}{*}{$\begin{array}{c}\text { Time of } \\
\text { Peak Plasma } \\
\text { Concentra- } \\
\text { tion } \\
\text { (min) }\end{array}$} & \multicolumn{2}{|c|}{$\begin{array}{c}\text { Urinary Excretion of Total } \\
\text { Unchanged and } \\
\text { Conjugated Paracetamol }\end{array}$} \\
\hline & & & $\underset{(\mathrm{mg})}{0-12 \mathrm{hr}}$ & $\underset{(\mathrm{mg})}{0-24 \mathrm{hr}}$ \\
\hline $\begin{array}{l}\text { Before metoclopramide } \\
\text { After metoclopramide }\end{array}$ & $\begin{array}{l}12.5 \pm 6 \\
20.5 \pm 4\end{array}$ & $\begin{array}{r}120 \pm 25 \\
48 \pm 12\end{array}$ & $\begin{array}{l}1,066 \pm 17 \\
1,016 \pm 23\end{array}$ & $\begin{array}{l}1,175 \pm 27 \\
1,116 \pm 18\end{array}$ \\
\hline
\end{tabular}

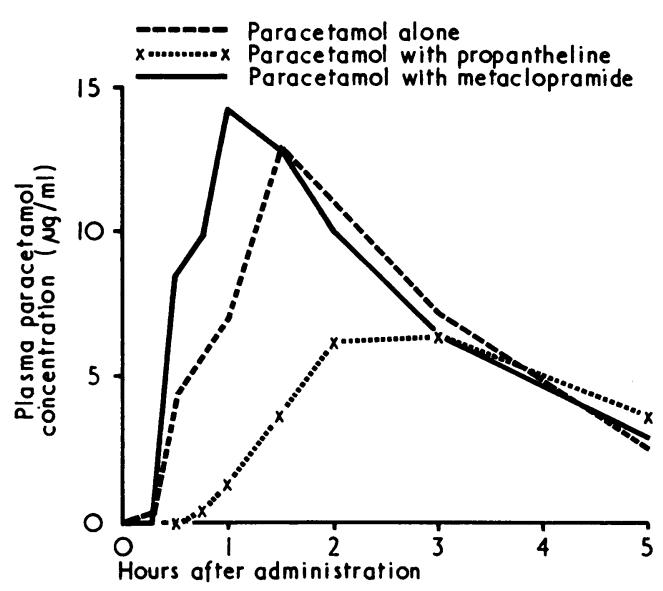

FIG. 3-The effect of propantheline and metoclopramide on paracetamol absorption in a 22-year-old man.

delay in the absorption of paracetamol. As in the healthy volunteers, the rate of paracetamol absorption was increased by metoclopramide.

\section{Discussion}

Factors such as the presence of food and the volume, tonicity, and viscosity of gastric contents are known to alter the rate of gastric emptying in man (Hunt, 1958) and these factors can also influence drug absorption (Levy and Jusko, 1965; Levine, 1970; Kojima et al., 1971). Since paracetamol is a weakly acidic drug (pKa 9.5) it is largely unionized both in the stomach and small intestine and should be well absorbed from both sites (Schanker et al., 1957). However, the gastric absorption of paracetamol in man is very slow and there is a highly significant correlation between the rate of gastric emptying and the rate of paracetamol absorption (Heading et al., 1973).

Many drugs have intrinsic pharmacological actions on gastrointestinal motility and might therefore influence drug absorption through effects on gastric emptying. Examples include atropine and other anticholinergics, anticholinesterases, tricyclic antidepressants, antihistamines, sympathomimetics, antihypertensives, and opiate analgesics. Little is known of the effects of these compounds on the absorption of other drugs in man. Hurwitz and Sheehan (1971) found that aluminium hydroxide 
delayed pentobarbitone absorption in rats and attributed this to retarded gastric emptying. Therapeutic doses of aluminium hydroxide, however, had no significant effect on paracetamol absorption in six healthy volunteers. If anything, absorption was more rapid after the antacid (J. Reid and J. Nimmo, unpublished observations, 1973). Like atropine, propantheline has inhibitory effects on the motor activity of the stomach and small intestine and delays the absorption of riboflavine (Levy et al., 1972). Similarly, atropine delays the absorption of orally administered lignocaine (Adjepon-Yamoah et al., 1973) and tricyclic antidepressants slow down the absorption of phenylbutazone (Consolo et al., 1970).

In the present study propantheline markedly reduced the rate of gastric emptying and the absorption of paracetamol was significantly delayed as judged by plasma concentrations and urinary excretion of the drug. Propantheline did not alter the total amount of drug excreted in 24 hours and probably did not alter the total amount absorbed. On the other hand, metoclopramide increases gastric peristalis and relaxes the pyloric canal thus shortening the gastric emptying time (James and Hume, 1968; Howarth et al., 1969). The rate of paracetamol absorption was correspondingly increased. Propantheline and metoclopramide were given at times likely to produce maximum effects on paracetamol absorption on the basis of their expected duration of action. Further studies are required to establish the effect of varying the time interval between administration of paracetamol and propantheline or metoclopramide.

Drug-induced changes in the rate of gastric emptying should have therapeutic significance if rapid absorption is required or if toxicity is associated with high drug plasma concentrations. The important role of gastric emptying in the absorption of orally administered drugs has other clinical implications. We have observed grossly impaired paracetamol absorption in patients with gastric stasis due to pyloric stenosis, and in such patients drugs should probably be given parenterally rather than by mouth.

Our thanks are due to Mrs. N. Henderson and Mr. A. J. Laidlaw for technical help. This work was supported by a grant from the Scottish Hospitals Endowment Research Trust.

\section{References}

Adjepon-Yamoah, K. K., Scott, D. B., and Prescott, L. F. (1973). British fournal of Anaesthesia. In press.

Brodie, B. B. (1964). In Absorption and Distribution of Drugs, ed. T. B. Binns, p. 16. Baltimore, Williams and Wilkins.

Consolo, S., Morselli, P. L., Zacala, M., and Garratini, S. (1970). European fournal of Pharmacology, 10, 239.

Heading, R. C., Tothill, P., Laidlaw, A. J., and Shearman, D. J. C. (1971). Gut, 12, 611.

Heading, R. C., Nimmo, J., Tothill, P., and Prescott, L. F. (1973). British Journal of Pharmacology. In press.

Hogben, C. A. M., Schanker, L. S., Tocco, D. J., and Brodie, B. B. (1957). Fournal of Pharmacology and Experimental Therapeutics, 120, 540.

Howarth, F. H., Cockel, R., Roper, B. W., and Hawkins, C. F. (1969). Clinical Radiology, $20,294$.

Hunt, J. N. (1958). In Modern Trends in Gastroenterology, ed. F. Avery-

Jones, p. 163. London, Butterworth.
Hurwitz, A., and Sheenan, M. B. (1971). Fournal of Pharmacology and Experimental Therapeutics, 179, 124.

James, W. B., and Hume, R. (1968). Gut, 9, 203.

Kekki, M. et al. (1971). International fournal of Clinical Pharmacology, 5, 209.

Kojima, S., Smith, R. B., and Doluisio, J. T. (1971). Fournal of Pharmaceutical Sciences, 60, 1639.

Levine, R. R. (1970). American Fournal of Digestive Diseases, 15, 171.

Levy, G., and Jusko, W. J. (1965). Fournal of Pharmaceutical Sciences, $54,219$.

Levy, G., Gibaldi, M., and Procknal, J. A. (1972). Fournal of Pharmaceutical Sciences, 61, 798 .

Magnussen, M. P. (1968). Acta Pharmacologica et Toxicologica, 26, 130.

Prescott, L. F. (1971). Fournal of Pharmacy and Pharmacology, 23, 807.

Prescott, L. F., and Nimmo, J. (1971). Acta Pharmacologica et Toxicologica 29, Suppl. No. 3, p. 288 .

Schanker, L. S., Shore, P. A., Brodie, B. B., and Hogben, C. A. M. (1957). Fournal of Pharmacology and Experimental Therapeutics, 120, 528 .

Siurala, M., Mustala, O., and Jussila, J. (1969). Scandinavian fournal of Gastroenterology, 4, 269.

\section{PRELIMINARY COMMUNICATIONS}

\section{Treatment of Chondromalacia Patellae by Transposition of the Tibial Tubercle}

\author{
MICHAEL DEVAS, ALEXANDER GOLSKI
}

British Medical fournal, 1973, 1, 589-591

\section{Summary}

The first 20 patients treated by transposition of the tibial tubercle for chondromalacia of the patella are reported. The patients, usually adolescent girls, had failed to respond to conservative measures. Seventeen patients benefited from the operation and three did not.

\section{Introduction}

Chondromalacia of the patella is a common and disabling condition of uncertain aetiology and unpredictable natural history. It often presents in adolescent girls keen on sport, in whom

Royal East Sussex Hospital, Hastings, Sussex

MICHAEL DEVAS, M.B., F.R.C.S., Consultant Orthopaedic Surgeon

ALEXANDER GOLSKI, M.B., F.R.C.S., Orthopaedic Registrar (Present address: Aldred Hospital Melbourne, Australia) conservative treatment including restriction of activity, nonresistant knee exercises, short-wave diathermy, and plaster immobilization often fails (Wiles et al., 1956). Drilling or shaving of the patellar cartilage occasionally gives a good result for a localized lesion but in general has been discarded (Wiles et al., 1960: Duthie and Hutchinson, 1958). The removal of an abnormally high ridge on the medial femoral condyle which is present in some cases has been advised by Outerbridge (1961). Excision of the patella, although it may get rid of the symptoms of the chondromalacia, is too drastic for an athlete (Cave and Rowe, 1950).

The treatment of chondromalacia of the patella by transposition of the tibial tubercle has been successful in the adolescent, and the method and early results are given here.

\section{Clinical Findings}

Pain, stiffness, and intermittent swelling of the knee with a feeling of insecurity or "catching" were the usual complaints. True locking or giving way of the knee so that the patient fell to the ground was not seen.

All the patients suffered pain on pressing and manipulating the patella against the femur; the undersurface of the patella was always tender to the pressure of the palpating finger (Devas, 1960). Some patients had scars from previous menisectomies.

Failure to relieve symptoms by conservative measures over some four to six months was the usual indication for tibial tubercle transposition. A few patients were over 20 years of age at the time of the operation. 